\title{
Artigo
}

\section{A imitação e o pensamento político brasileiro: uma análise das obras de Oliveira Vianna e de Guerreiro Ramos}

\author{
The imitation and the Brazilian political thought: \\ an analysis of the works of Oliveira Vianna and \\ Guerreiro Ramos
}

\author{
Marcelo Sevaybricker Moreira \\ Professor Adjunto, Universidade Federal de Lavras (UFLA), \\ Lavras, MG, Brasil \\ marcelomoreira@dch.ufla.br, msevay@gmail.com
}

Resumo: Este artigo assume a hipótese de que o tema da imitação é essencial para se compreender não apenas a obra de alguns pensadores políticos, como Oliveira Vianna e Guerreiro Ramos, aqui escolhidos para análise, mas a própria formação do "pensamento político brasileiro", enquanto objeto e também como campo de estudos científicos. Defendemos a ideia de que a forte presença da disjuntiva entre imitação e autenticidade na inteligência nacional é decorrente da história colonial e da condição periférica do país, que não é superada com a independência em 1822. Essa disjuntiva, utilizada como estratégia argumentativa por Vianna e Ramos, está associada ao discurso nacionalista adotado por ambos, ainda que com conotações políticas bastante diferentes. Sem poder avaliar a questão da imitação de modo mais sistemático, o trabalho conclui sugerindo algumas perspectivas de investigação na área de estudos de pensamento político brasileiro que considerem mais centralmente a ideia de periferia na formação de uma teoria política nacional.

Palavras-chave: Imitação; Periferia; Nacionalismo; Pensamento político brasileiro.

\footnotetext{
Abstract: This article assumes that the subject of imitation is essential to understand not just the work of some political thinkers, like Oliveira Vianna and Guerreiro Ramos, here chosen for analysis, but the own formation of the "Brazilian political thought", while object and also as a field of scientific studies. We defend the idea that the strong presence of disjunctive between imitation and authenticity in national intelligence is a result of colonial history and
} 
the peripheral condition of the country, which is not overcome with independence in 1822. This disjunctive, used as argumentative strategy by Vianna and Ramos, is associated with the nationalist discourse adopted by both, although with quite different political connotations. Unable to evaluate the question of imitation of more systematic way, the work concludes by suggesting some prospects for research in the field of study of Brazilian political thought they deem more centrally the idea of periphery in the formation of a national political theory.

Keywords: Imitation; The periphery; Nationalism; Brazilian political thought.

O escritor português Eça de Queiroz costumava criticar com frequência seus pares por se basearem na imitação de modelos estrangeiros. Ironicamente, O primo Basílio e O crime do Padre Amaro, duas de suas obras-primas, foram criticadas pela pena de Machado de Assis não apenas por aderirem aos modismos literários da época, como também por serem plágios, respectivamente, d'Eugénie Grandet, de Honoré de Balzac, e d'O Crime de Padre Mouret, de Émile Zola.

Se o tema da imitação ou cópia parece ser indissociável da formação da literatura do Brasil - caracterizada por Antonio Candido como "[...] um galho secundário da portuguesa, por sua vez, arbusto de segunda ordem no jardim das Musas" (CANDIDO, 2009, p. 11) - talvez, o mesmo possa ser dito, de um modo geral, acerca do pensamento político brasileiro.

O propósito desse artigo é explorar minimamente os usos desse tema por alguns intelectuais brasileiros, sobretudo, por aqueles preocupados em organizar racionalmente e modernizar a política nacional e que, et pour cause, se esforçaram em estudar, identificar e simultaneamente criar uma linhagem de um pensamento autêntico para o país. Sem qualquer pretensão de dar um tratamento exaustivo à questão da imitação, escolhemos dois momentos da república e da formação do pensamento brasileiro para debatê-la.

O primeiro se refere à adequação das instituições políticas republicanas e das ideias que as justificam no contexto brasileiro de início do século XX, em substituição à tradicional monarquia. Para isso, avaliaremos as críticas formuladas por Oliveira Vianna ao liberalismo brasileiro e às instituições e ideias republicanas, nas quais o tema da imitação é central para sua argumentação.

O segundo momento de análise diz respeito a um período subsequente da república, qual seja, o de nossa primeira experiência democrática (1945-64) e do debate nacionaldesenvolvimentista. Para pensar como o argumento da cópia é mobilizado nesse contexto, recorremos à obra do sociólogo baiano Guerreiro Ramos, para quem a disjuntiva cópia versus autenticidade é central no entendimento do Brasil e de seus diversos impasses. 
A hipótese do artigo é que a relevância da imitação na imaginação política brasileira, ainda que sempre referida a contextos históricos e discursivos distintos, é decorrente de nossa formação periférica, quer dizer, embora o país já tivesse se tornado independente formalmente de sua metrópole há mais de um século, a questão da autonomia do país, perante à ordem global e às nações tidas como mais avançadas, perpassa o período republicano como um "fantasma" a ser exorcizado, conforme ponderou Christian Lynch (2013).

Não apenas a imitação é um assunto privilegiado por vários de nossos analistas políticos, tornando-se uma estratégia retórica comum em diferentes debates públicos, que serve, portanto, para o confronto e deslegitimação dos argumentos dos adversários, como é, por assim dizer, um traço de origem do pensamento político nacional, concebido segundo dois sentidos: o primeiro referindo-se às próprias ideias e discursos formulados sobre o país e, o segundo, concernente à criação de um campo de investigação que tem nessas ideias e discursos o seu objeto de estudo.

O percurso do presente trabalho inicia-se por uma contextualização do tema da imitação, recuperando brevemente as obras de dois intelectuais que dissertaram sobre essa temática: Roberto Schwarz, com a conhecida "As ideias fora do lugar", e Raymundo Faoro, em Existe um pensamento político brasileiro?. Em seguida a esse introito, passamos propriamente à análise das obras de Vianna e Ramos. Por fim, teceremos algumas considerações sobre as possibilidades interpretativas de se tomar a imitação ou cópia como chave de leitura do pensamento político brasileiro.

\section{Um Brasil inautêntico: Schwarz e Faoro}

Em ensaio publicado em 19771, no contexto de um debate mais amplo sobre a dependência como traço comum aos países latino-americanos, o crítico literário Roberto Schwarz assume a inautenticidade como chave explicativa para se pensar o Brasil. Segundo ele, a "impropriedade de nosso pensamento" (SCHWARZ, 1973, p. 160-161) é uma marca do país, evidenciado pela disparidade entre os ideais liberais, copiados dos países capitalistas centrais e professados desde a Constituição de 1824, e o regime de escravidão mantido até 1888.

1 O artigo original é, na realidade, de 1973, reproduzido posteriormente como primeiro capítulo do livro Ao vencedor as batatas, cuja primeira edição data do anos de 1977. 
Como prova dessa inautenticidade do liberalismo brasileiro, o autor assevera que o "favor" - e não os direitos - acabou se constituindo como o operador central da mediação social entre os homens livres (esses, sim, dotados de direitos) e os seus dependentes. Schwarz avalia que, curiosamente, no Brasil oitocentista, o teste de realidade parecia não importar em nada, pois se não havia compatibilidade entre ideário liberal e a realidade escravocrata, o problema, para os intelectuais e políticos do país, deveria estar no primeiro.

Na realidade, é bom lembrar que, na Europa, o liberalismo, enquanto uma ideologia, também não se conformava à realidade. Mas lá, assevera Schwarz, os interesses e antagonismos de classe eram disfarçados pelo ideal da cidadania, de liberdade, etc., pretensamente universais. A diferença é que aqui, ao invés de encobrir a exploração de classe, elas não mascarariam coisa alguma, uma vez que nem relações capitalistas propriamente ditas existiriam no Brasil. Essas ideias, portanto, seriam falsas porque inorgânicas, ou, nos termos desse autor, porque "fora do lugar".

Dialeticamente, Schwarz nota que apesar de ser uma falsidade ideológica, o liberalismo brasileiro acabou se constituindo em um fator efetivo da realidade nacional, pois passou a orientar, enquanto um ideal político, as elites e a vida social do país, como, por exemplo, durante a campanha abolicionista. Mesmo como farsa, o liberalismo brasileiro se constituiu, enfim, em um fator decisivo na história do país.

Contraditoriamente, o país que queria ser liberal era, nas suas práticas, anti-liberal, práticas essas funcionais para o capitalismo. É sob essa condição peculiar, de colônia e de fornecedor de mão-de-obra escrava, que o país se inseriria na ordem mundial. Como nota Ricupero, a partir da interpretação de Schwarz, "[...] os resquícios coloniais não podiam ser facilmente associados ao atraso, ao passo que o novo, relacionado a nação independente, não seria necessariamente moderno" (RICUPERO, 2013, p. 529).

Recuperando o longo debate criado a partir da tese das "ideias fora do lugar", tese essa já várias vezes criticadas, Ricupero observa que Schwarz reconhece que o descompasso entre ideias liberais e realidade nacional já havia sido denunciado anteriormente. Entretanto, enquanto alguns intelectuais "conservadores" do país (como Oliveira Vianna, por exemplo) e pensadores ligados ao ISEB (como Guerreiro Ramos) identificaram como a causa desse descompasso o liberalismo em si, para o crítico literário uspiano o principal é que o arcabouço político institucional do país se modernizou e liberalizou após 1822, mas a estrutura socioecônomica continuava arcaica e escravagista, diferentemente dos países que serviam de modelo ao Brasil. 
Transmutado para os trópicos, o liberalismo acabou não se constituindo em uma ideologia de direitos universais (que encobriria relações de trabalho assalariado e a sua exploração capitalista), e sim se acomodando ao domínio dos latifundiários e se convertendo em uma"[...] ideologia de segundo grau"(RICUPERO, 2008, p. 60). Não haveria, em suma, segundo o diagnóstico de Schwarz, um pensamento político propriamente brasileiro, a não ser como ornamentação das elites².

Quase duas décadas após o conhecido ensaio de Schwarz, o livro Existe um pensamento político brasileiro ${ }^{3}$, de Raymundo Faoro, retoma essa temática em termos similares, ao dissertar também sobre as peculiaridades e agruras da cultura política nacional. Esse autor associa diretamente a questão da (in)existência de um pensamento nacional à questão da imitação. Diz ele:

Se há um pensamento político brasileiro, há um quadro cultural autônomo, moldado sobre uma realidade social capaz de gerá-lo ou de com ele soldar. Nesta parte, é oportuna a reflexão, dentro da farta bibliografia, da imitação, da cópia, da importação de paradigmas e modelos culturais. (FAORO, 2007, p. 29).

Ojurista de Vacaria, partindo de uma tradição de pensamento liberal e constitucionalista, e avaliando a formação da inteligência nacional como um desdobramento da cultura política lusitana, infensa ao lluminismo e ao liberalismo e que não se constituiu numa prática política liberal, chega igualmente à polêmica conclusão de que não há um pensamento político propriamente brasileiro. Por aqui, a preocupação da tradição liberal não era proteger o indivíduo perante o Estado, diz Faoro, mas conciliar os interesses da burguesia incipiente aos da aristocracia rural, de modo que o Estado é um "[...] um monstro patrimonial-estamental-autoritário" do qual toda sociedade continuaria dependente (FAORO, 2007, p. 85).

O que esse autor quer polemicamente destacar é que a tradição liberal não completou sua formação enquanto pensamento político (interditado desde cedo pelo sopro antiiluminista que grassou na nação lusitana), a orientar efetivamente a práxis política, de modo que são outros os discursos que acabaram imperando no país. Poderíamos, nos termos de Faoro, ter uma filosofia política e mesmo uma ciência política liberais, mas

2 Lynch (2013, p. 758).

3 A primeira edição data de 1994. 
não um pensamento político liberal. Curioso notar que Faoro, um liberal, ao concluir pela inexistência de um liberalismo genuinamente brasileiro deduz a ausência de qualquer pensamento político no país, ausência essa fortemente contestada por estudos já publicados a essa época (SANTOS, 1978).

Concluindo, tanto para Faoro quanto para Schwarz, à luz das matrizes liberais originárias, europeias e estadunidenses, o fato do liberalismo brasileiro ter se constituído em uma "farsa das elites", evidenciando "o caráter ornamental do saber e da cultura" nacionais está na raiz da inautenticidade cultural brasileira, como um todo.

Não se tem a vã pretensão de no espaço desta seção propor alguma resposta alternativa a Schwarz e Faoro, ou de avaliar todos os desdobramentos desse debate na cultura nacional. Na realidade, recorre-se aqui as suas obras apenas para atestar que alguns intérpretes já haviam salientado a cópia de ideias e instituições como um problema central num país como o Brasil.

Mas além disso, pretende-se enfatizar que o desiderato da presente proposta é outro: não importa aqui contrastar a realidade nacional às ideias "importadas", compreendendo negativamente esse processo, mas antes constatar alguns modos e contextos diferenciados em que o debate sobre a imitação emerge no pensamento político brasileiro e o que eles tem a nos dizer acerca desse último.

Assume-se aqui que a imitação não apenas é um tema recorrente de nossos discursos políticos, mas é um fenômeno constitutivo da própria realidade brasileira. Seguindo as pistas de Reinhart Koselleck (2006), observa-se que não há uma determinação unilateral e mecânica entre realidade (pragmata) e linguagem (dogmata). Os conceitos são, ao mesmo tempo, indicadores e fatores da realidade: se eles "refletem" as mudanças e a estabilidade do real, também são parte constitutiva delas. Nesse sentido, independentemente de ser ou não verdade de que "não há um pensamento político brasileiro", a ideia da inautencidade a que se refere esse tipo de discurso fez parte e expressa, simultaneamente, a realidade nacional.

\section{Oliveira Vianna: a crítica à utopia liberal-republicana}

Em O idealismo da Constituição, Oliveira Vianna assevera que um dos principais problemas do Brasil é que, por aqui, dominam os idealistas para os quais a experiência não tem valor algum. Eles tem feito da política uma arte silogística, puramente abstrata. 
O autor, obviamente, se proclama um idealista de outro tipo. Como ele diz, os cem anos de democracia no Brasil valeram "[...] como uma mina de valor inestimável, rica do mais puro minério informativo" (VIANNA, 1939, p. XIII) para que ele formulasse um outro tipo de pensamento.

Ele diferencia duas formas de idealismo: o utópico e o orgânico. O primeiro consiste em "[...] todo e qualquer sistema doutrinário, todo e qualquer conjunto de aspirações políticas em íntimo desacordo com as condições reais e orgânicas da sociedade" (VIANNA, 1939, p. 10). O idealismo orgânico não é, por outro lado, condenável, e resulta da "[...] própria evolução orgânica da sociedade e não é outra coisa senão visões antecipadas de uma evolução futura" (VIANNA, 1939, p. 11).

Para ele, todas as constituições promulgadas até hoje no Brasil, de 1824 até 1934, fracassaram porque "[...] nenhuma dessas construções se assentou sobre bases argamassadas com argila de nossa realidade viva"(VIANNA, 1939, p. XIV). Como se sabe, o argumento desse pensador redunda na defesa da Constituição de 1937 e do Estado Novo, supostas expressões, por outro lado, de um idealismo orgânico. Mas vejamos como esse autor chega a essas conclusões.

Como se sabe, desde Populações meridionais do Brasil Vianna afirma que nossa formação social, marcada pela ruralidade, latifúndio, dispersão populacional ao longo do território, hibridismo racial, etc., produziu um padrão societário insolidário. O "clã rural" (fundamento, por seu turno, do "clã parental"e, após a República, do "clã eleitoral"), célula matricial de nossa sociedade, produziu uma cultura política privatista e localista, precisamente o contrário do que ocorrera nos países desenvolvidos, como Inglaterra e Estados Unidos, nos quais a sociabilidade predominante constituiu um mundo público a integrar todo o território nacional - condição sine qua non para o bom funcionamento das instituições liberal-democráticas (VIANNA, 2005).

Em Instituições políticas brasileiras, Vianna utilizando-se de outras categorias conceituais, afirma que, nos países do Atlântico Norte, as leis positivas criadas pelo Estado são produtos que se harmonizam e reforçam os costumes longevos praticados por seus povos, ao passo que no Brasil elas são tomadas de "empréstimo" de outros lugares, sem necessariamente serem compatíveis com o contexto social local (VIANNA, 1995).

Nesse sentido, como nota Gildo Brandão, para Vianna, o projeto republicano-federativo teria reforçado "[...] nossas características mais negativas - a anarquia branca, o predomínio 
das oligarquias, o risco de fragmentação do país" (BRANDÃO, 2010, p. 119). Assim, ainda que o ideário liberal-republicano, de origem estrangeira, sejam em si mesmos louváveis, quando transplantados para o continente latino-americano, produzem o contrário do que preconizam: não a liberdade do cidadão, mas a sua contínua submissão ao poder privado dos clãs eleitorais; não a ordem, mas a violência entre as famílias a disputar o poder local.

Embora não haja espaço para uma discussão sistemática e que percorra toda a obra de Oliveira Vianna, parece-nos interessante a interpretação de Wanderley Guilherme dos Santos, para quem a teoria política do primeiro é expressão de um projeto que concebe o Estado centralizador como condição necessária para criar uma ordem liberal no Brasil. A tese do "autoritarismo instrumental" consiste em afirmar que Vianna, ao contrário dos "liberais doutrinários", tinha como horizonte normativo a universalização dos direitos civis e sociais à população brasileira, mas não dos direitos políticos, a fim de evitar o equívoco da simples imitação das instituições estrangeiras sem qualquer forma de adaptação ao contexto nacional (SANTOS, 1978).

Mesmo em interpretação concorrente à de Santos, como a tese acerca do iberismo e do americanismo, formulada por LuizWerneck Vianna, também reconhece na imitação um critério fundamental à compreensão do pensamento brasileiro. Segundo Werneck Vianna, o jurista fluminense seria expressão de uma tradição de interpretação do Brasil denominada de iberista. Ao contrário dos americanistas, como Tavares Bastos ou Rui Barbosa, para pensadores como Oliveira Vianna dever-se-ia valorizar a "opção ibérica" como uma alternativa de civilização às condições sociais dos trópicos. Ao contrário de um Estado descentralizado e uma sociedade civil forte, idealizado acriticamente pelos americanistas, os iberistas advogavam a necessidade de um Estado nacional forte como única via, não de modernização liberal (como quer Santos), mas de construção de uma ordem social estável e harmônica. Nesse sentido, ainda que Oliveira Vianna seja visto como um autor crítico do ideário liberal moderno, ele ainda formula seu projeto iberista em oposição à tendência imitativa dos americanistas, conforme a leitura de Werneck Vianna (2004).

Retomando o fio da argumentação do próprio Oliveira Vianna, o principal erro daqueles que simplesmente copiavam as ideias e instituições estrangeiras, esperando que elas tivessem aqui o mesmo efeito, é que eles desconsideravam o fato capital de que "[...] no Brasil não existia povo no sentido anglo-saxão da expressão, isto é, massas 
populares esclarecidas e independentes"(VIANNA, 1939, p. 60-61). Polemicamente, esse autor acusa os republicanos de "legislarem por abstrações", tomando o brasileiro como um cidadão em potencial, tal como na filosofia rousseauniana, quando não passava de um “boneco metafísico" (VIANNA, 1939, p. 417). O "espírito de clã”, e não a cultura cívica, alerta o jurista fluminense, é a verdadeira alma brasileira.

Verificar-se-ia, dessarte, um "quixotismo", quer dizer, um intelectualismo difuso e superficial entre as elites, caracterizado pelo excesso de imaginação e pelo beletrismo. É precisamente no conflito entre o "espírito de clã" e o quixotismo latino que reside a causa do fracasso de nossas instituições políticas. Embora o quixotismo seja, para Vianna, um traço comum a várias Constituições, é preciso ter clareza que ele dirige suas críticas sobretudo contra a de 1891, que pôs fim a um governo político estável, dirigido por indivíduos mais qualificados para a res publica, os "homens de 1.000". Como crentes no poder místico das leis, acreditam que por decreto criariam uma democracia no Brasil, do mesmo como se fosse possível transformar, num passe de mágica, os brasileiros em budistas.

Em decorrência de seu idealismo utópico, os liberais-republicanos, aliás um grupo com apoio muito débil na sociedade brasileira, não compreenderam porque seus ideais fracassaram, continua Vianna. Nesse grupo, predominava a crença de que as dificuldades da república eram causadas pelos vícios do povo brasileiro, o que os levava a condenálo moralmente pela sua inadequação a modelos de sociabilidade que, obviamente, em nada se assemelhavam aos seus originalmente. Havia, entretanto, os mais tolerantes que diziam que o regime não fracassara de todo; seria apenas uma questão de tempo: "[...] e ainda hoje os seus epígonos continuam a esperar messianicamente na ação do grande milagreiro", ironiza Vianna (1939, p. 93).

De qualquer modo, a crítica de Oliveira Vianna consiste em denunciar a ignorância frequente dos intelectuais e políticos em relação ao próprio país, o que os levava a adotar uma postura moralista e demofóbica4 . Sarcasticamente, ele afirma que o brasileiro, em

4 É evidente que o pensamento de Vianna é expressão também de um tipo de demofobia, o que se revela pelos comentários aristocráticos em suas diversas obras. Por isso, mas também por crer ser inviável um projeto político puramente liberal para o país, Vianna é contrário à adoção do sufrágio universal. A esse respeito, diz ele: "O grosso de nossa massa eleitoral não tem, portanto, independência de opinião. Ora, os meios mais eficazes para assegurar essa independência não serão, por certo, o 'sufrágio universal', nem a 'eleição direta', nem o 'voto secreto', nem o 'self-government local'; mas, sim, outros meios de natureza econômica e social: o estabelecimento da pequena propriedade; um sistema de arrendamentos a longo prazo ou um regime de caráter enfitêutico; a difusão do espírito corporativo e das instituições de solidariedade social; uma organização judiciária expedita, pronta e eficaz; uma magistratura autônoma, com força moral e material para dominar o arbítrio os mandões locais, etc." (VIANNA, 1939, p. 112-113). 
geral, raciocina corretamente até o momento em que o ensinam o francês, bem como "as ideias adiantadas" da época. Daí então, "[...] ele nos olha num estado de imbecilização sonambúlica" (VIANNA, 1995, p. 413).

Brandão salienta corretamente que "[...] o inimigo de Oliveira Vianna é sempre o bacharelismo, os políticos e juristas liberais que [...] raciocinam livrescamente"5. Para nosso autor, o quixotismo nacional é consequência direta do modo pelo qual nossas elites foram educadas, isto é, por religiosos sem qualquer formação objetiva ou positiva de ciência. Educados no exterior, querem organizar o país segundo os ideais europeus, não conforme as disposições reais do povo brasileiro. Conhecem profundamente os males estrangeiros, mas são "analfabetos" no que concerne ao seu país. Para Vianna, ainda que houvessem importantes exceções a esses irrealistas (como Visconde de Uruguai, Barão de Rio Branco, Alberto Torres, etc.), foi esse tipo de idealismo que vicejou no país, estendendo-se até a República, inclusive por conta da difusão de tal ideário através da imprensa nacional.

Na concepção desse autor é nos costumes e práticas há muito consolidadas no povo-massa que se encontra o verdadeiro direito brasileiro, o "direito-costume", nascido no meio rural a regular a vida do "país real" (com suas respectivas instituições, tais como o banditismo, o coronelismo, o caudilhismo, etc.), e não o "direito-lei" ou o "direito público", cultuado pelas elites, só cientes do que se passa no litoral.

O outro lado da moeda de sua argumentação crítica ao liberalismo e republicanismo brasileiro é a defesa da Carta Constitucional de 1937, isto é, aquela que consolida a ditadura varguista no país. Mas Vianna não a descreve exatamente nesses termos. Em primeiro lugar, diz ele, ela não é menos democrática que as demais; apenas diminuiu o poder do Legislativo que, afinal, já havia se transformado em um palco de lutas estéreis e facciosas. Os partidos, justifica ele, pulverizados após 1934, não apenas não representavam ninguém, como ademais, alimentavam a desordem, especialmente os de orientação comunista. Em segundo lugar, o golpe de 37 teria sido a única forma viável de garantir a ordem nacional, aumentando o poder e a competência da União, garantindo o primado do Executivo em relação aos outros poderes e ampliando a base democrática do governo por meio da instituição do Conselho da Economia Nacional, corpo técnico e corporativo que funcionaria como órgão consultivo ao Presidente da República. Defendendo a nova 
ordem então criada, Vianna recorre à expressão "democracia autoritária", cunhada pelo nazista Joseph Goebbels (VIANNA, 1939, p. 149).

Mas, ao contrário do que pode parecer, o Estado Novo não representava para o autor a vitória plena do idealismo orgânico, pois a despeito dos seus avanços, teria incorrido nos erros de manter o modelo federativo e o Congresso nacional em funcionamento. A utopia realista de Vianna só seria totalmente realizada por um modelo da democracia corporativa, na qual o presidente não precisaria mais assegurar a coalizão no Parlamento, mas, assessorado por técnicos, organizaria "de cima para baixo" os interesses genuinamente nacionais.

De qualquer modo, o que importa aqui é que em sua defesa da Constituição de 37, ele que participara da Assembleia Constituinte de 34, Vianna antecipa-se à crítica daqueles que veem no Estado Novo ou na Consolidação da Legislação Trabalhista, uma imitação de instituições estrangeiras, como a Carta del Lavoro. Elas não foram, defende-se o autor de seu próprio veneno, criadas silogisticamente, mas a partir de um método objetivo e sociológico, "[...] de sondagem direta às subcamadas de nossa vida social e jurídica, antes de sua transubstanciação em lei" (VIANNA, 1995, p. 33).

Comparado aos "americanos e ingleses", os brasileiros, pondera essa autor, vivem um drama peculiar por terem se constituído por "transplante ou enxertia cultural" (VIANNA, 1995, p. 95), a separar, desde a origem, a cultura ilustrada das elites, formada de empréstimo de outros povos, e a cultura política do povo-massa (formada segundo as condições sociais e raciais próprias ao país). É isso o que explicaria também o nosso "complexo de inferioridade em face da cultura europeia ou anglo-americana" e a nossa "obsessão" por modelos estrangeiros.

Como se vê, se em O idealismo da Constituição as principais causas do idealismo utópico são a educação europeia, a influência da imprensa sobre as elites, bem como a ignorância dessa última em relação ao Brasil "real", em Instituições políticas brasileiras, o autor, à época "influenciado" pelos desenvolvimentos das ciências sociais no que tange ao conceito de cultura, acrescenta às primeiras causas a ignorância de nossas elites quanto às leis culturológicas e a crença infundada no poder criador das leis positivas.

Pode-se dizer que a obra de Vianna, como um todo, revela a preocupação do autor com o tema da imitação, referido tanto às ideias quanto às instituições políticas. Nesse sentido, salta aos olhos o esforço do autor em criticar (nem sempre de modo justo) os 
"idealistas utópicos" e em encontrar precedentes, na tradição intelectual do país, de uma vertente de pensamento autenticamente brasileiro.

\section{Guerreiro Ramos: contra uma sociologia "enlatada"}

Pode-se afirmar que a questão central da obra de Guerreiro Ramos é formular um pensamento adequado às condições brasileiras. Para ele, a formação de uma sociologia nacional caminharia pari passu à formação de um capitalismo autônomo no país (BARIANI JUNIOR, 2008, p. 11). Sendo assim, o autor concebe a sociologia como um "saber de salvação" (RAMOS, 1996, p. 11), a contribuir na transformação do país em uma nação moderna e independente. Nesse sentido, Ramos se assemelha ao pensamento de Vianna no que diz respeito: 1) à recorrência ao topos argumentativo da imitação; 2) no "esforço revisionista" de autores do passado, a fim de identificar uma corrente crítica, não-imitativa, na tradição intelectual do país e, por fim; 3) à concepção da ciência como um instrumento prático a fomentar a transformação do país. Mas vejamos os modos pelos quais a imitação aparece na obra de Guerreiro Ramos.

Em primeiro lugar, cumpre notar que a crítica à cópia na obra desse pensador emerge na análise da própria sociologia brasileira feita principalmente nos anos 50. Apesar de identificar a emergência de uma"nova consciência nacional", essa ciência, tal como praticada no Brasil, caracteriza-se pelo seu caráter "reflexo", isto é, sua mentalidade ainda "colonial". Boa parte dos sociólogos brasileiros em pleno século XX assimilam ou transplantam literal, passiva e ingenuamente os produtos científicos importados, produzindo uma ciência ignorante quanto às reais necessidades do país e, por conseguinte, disfuncional - o que ele denomina de "sociologia consular" ou "enlatada".

O autor ilustra seu argumento referindo-se à adoção de conceitos da sociologia estadunidense, tal como o de "controle social", importante numa nação já desenvolvida, mas completamente despropositado num país como o Brasil, que viveria ainda em condição de subdesenvolvimento e de necessária transformação. Aqui, assevera Ramos, o conceito que se impõe como essencial para a modernização do país é o de "mudança social", e não o de "controle".

Ao invés de sociologia como"repetição", supervalorizada como"hábito"e como mera "informação", Ramos defende a"redução sociológica", que seria o método mais adequado 
do fazer científico e que, todavia, seria negado pela maioria dos nossos intelectuais. Esse método se define por quatro leis fundamentais: 1) a do "comprometimento", segundo a qual o cientista se engaja sistematicamente tanto com o desenvolvimento do saber científico, quanto da sua nação, se negando a desempenhar o papel de mero "copista"; 2) a do "caráter subsidiário da produção estrangeira", que impede o sociólogo de um determinado país de viver refém das "modas" intelectuais, transformando-o de um "consumidor" ou "colecionador" em um produtor de ideias; 3) a da "universalidade dos enunciados gerais da ciência", que submete o trabalho científico às necessidades e ao contexto da comunidade em que ele é realizado; 4) a das "fases", ou seja, o princípio que afirma que os problemas a serem investigados são sempre particulares à fase de desenvolvimento em que a sua sociedade se encontra (RAMOS, 1996, p. 115).

Tal como na obra de Vianna, a sociologia de Ramos representa uma denúncia cáustica ao modo como a intelligentsia atua no país - seu desconhecimento dos reais problemas do país e a admiração ingênua aos modelos estrangeiros, mantendo-se sempre em relação a eles"up to date" (RAMOS, 1957, p. 19). Sobre isso, o autor, em tons fortes, formula um diagnóstico próximo do "quixotismo" destacado por Vianna: por aqui vicejaria um "vício mental", uma "doença infantil" comum aos países coloniais que faz da sociologia mera "'gesticulação' vazia de significado" (RAMOS, 1957, p. 80). Por isso, continua ele, na América Latina, as nações estão submetidas a uma "deformidade culturológica", a um defeito de origem, na medida em que as instituições lá fixadas foram transplantadas de outros contextos, por "efeito de prestígio", e não resultaram da evolução interna e do "crescimento orgânico destes países" (RAMOS, 1957, p. 54).

O argumento da imitação aparece igualmente no debate estabelecido pelo autor a respeito do desenvolvimento nacional. Em geral, afirma esse autor, o grau de desenvolvimento de um país é aferido pelos seguintes critérios: distribuição da mão de obra pelos setores produtivos, renda nacional per capita, consumo per capita de energia, urbanização e industrialização (RAMOS, 1957, p. 157). Embora, como se vê, a sua obra seja bastante marcada pelo debate nacional-desenvolvimentista, Ramos contesta as teorias da modernização segundo as quais existiriam critérios universais válidos para avaliar o grau de desenvolvimento das diversas nações do orbe 6 . Por exemplo:

6 Entretanto, como nota Edison Bariani Junior (2008), Guerreiro Ramos compreende a industrialização quase como a própria modernidade, expressão do "processo civilizatório", independentemente a qual contexto se refira. 
nem sempre elevada renda nacional per capita implica em desenvolvimento. No que tange ao desenvolvimento, Ramos tem em mente um processo concreto, não apenas econômico, e que estava em vias de se materializar no Brasil dos anos 50-60; processo esse que implicaria na erradicação da miséria, da mortalidade infantil, na substituição de importações, no incremento tecnológico, na elevação de renda e na ampliação da democracia.

Defendendo a autenticidade das teses cepalinas, a crítica às "vantagens comparativas" e à "vocação agrícola" dos países latino-americanos (RAMOS, 1957, p. 97), o autor concebe que, assim como é necessário ao Brasil substituir a importação de produtos industrializados pela manufatura nacional, é mister desenvolver um pensamento brasileiro voltado para a real compreensão do país. Trocar minérios e conceitos "enlatados" por mercadorias tecnologicamente desenvolvidas e por teorias sociológicas funcionais à realidade brasileira (BARIANI JUNIOR, 2008).

A mesma ordem de preocupações perpassa a discussão feita por Guerreiro Ramos acerca do "problema do negro", na medida em que ele ataca duramente os intelectuais brasileiros que se tornaram especialistas nesse assunto, pois, supostamente, o investigam "[...] a partir de categorias e valores induzidos predominantemente da realidade europeia" (RAMOS, 1957, p. 123).

Com o fito de desmascarar a suposta alienação reinante, esse autor se volta aos estudos raciais brasileiros do fim do século XIX até aos da sua época, sobretudo, aos estudos financiados pela UNESCO. Ele diferencia três correntes fundamentais no estudo sobre o negro no Brasil, a saber: 1) uma de cunho monográfico, da qual seriam expoentes Nina Rodrigues, Gilberto Freyre, Arthur Ramos, Florestan Fernandes, entre outros, e que se caracteriza por definir o negro como "assunto" de especialistas, considerando-o como um fenômeno "estático"; 2) a corrente "crítico-assimilativa" em relação à ciência estrangeira, representada por Sylvio Romero, Euclides da Cunha, Alberto Torres e Oliveira Vianna, que, uma vez interessados em "extremar as características peculiares de cada um dos contingentes formadores da nação", acabaram contribuindo "[...] para arrefecer qualquer tendência para ser ele considerado sob o ângulo do exótico" (RAMOS, 1957, p. 127-128) e; 3) aquela voltada para a transformação real da condição do negro na sociedade brasileira, que ele próprio, Guerreiro Ramos, representaria. 
O aspecto a notar nessa recuperação do pensamento nacional empreendida pelo autor é a valorização das obras de Romero, Cunha, Torres e Vianna - autores cujas obras, ainda que de modo diferenciado, contém elementos racistas - e a desvalorização das obras da primeira corrente que, em geral, é considerada pelos estudos posteriores do pensamento brasileiro, como responsável pela superação (ainda que parcial) do racismo e pelo reconhecimento dos povos africanos na constituição da identidade nacional. Uma vez que Ramos se vale de um critério "externo" de avaliação das obras dos autores do passado nacional - a autonomia nacional - a sua peculiar interpretação do pensamento brasileiro acaba por condenar os intelectuais que foram responsáveis por uma renovação da sociologia brasileira a um lugar secundário na história da relações raciais no país.

Além disso, o mencionado racismo presente na segunda corrente, em autores como Oliveira Vianna, a quem ele chama de "mestre", é tratado por ele como um efeito não previsto de sua maior qualidade, "[...] a de fazer da sociologia instrumento de autodeterminação nacional" (RAMOS, 1957, p. 139). Ao defender a tese do branqueamento, Oliveira Vianna estaria tratando o negro como um indivíduo a ser integrado ao povo brasileiro, e não como elemento exótico. Nessa linha de raciocínio, autores supostamente mais atualizados em relação às ciências sociais internacionais, como Florestan Fernandes, tratam o negro como elemento "estático" e "externo" à cultura brasileira, numa chave, de acordo com Ramos, claramente mimética (por adotar a perspectiva do estrangeiro-colonizador) e, portanto, pior.

A terceira corrente de estudos raciais consistiria num esforço de sociologia prática, a combater o preconceito racial no país por meio da crítica à ideologia da brancura. A cópia, no caso da questão racial, desempenha nesse passo da argumentação um efeito duplamente negativo: produz uma sociologia equivocada (que replica teoria exógenas) e produz um ideal estético que contribui para uma patologia nacional, dado o perfil fenotípico majoritariamente não-branco da população brasileira.

A condição do negro no Brasil só é sociologicamente problemática em decorrência da alienação estética do próprio negro e da hipercorreção estética do branco brasileiro, ávido de identificação com o europeu. (RAMOS, 1957, p. 157).

O branco copia a estética europeia e os negros vivem segundo uma avaliação negativa de si mesmos. Nesse contexto, precisamente por se identificar como expressão de um 
nova corrente da sociologia brasileira (da qual seria expressão também a obra de Abdias do Nascimento), Guerreiro Ramos argumenta que uma consciência nacional finalmente emerge no país, conforme sugere também a criação do TEN (Teatro Experimental do Negro). Superada a fase da imitação - típica de países coloniais - "[...] a sociologia, no Brasil, está entrando em uma segunda etapa da evolução normal"(RAMOS, 1957, p. 105), adquirindo uma consciência crítica de si mesma, ciente dos condicionamentos a que a produção científica está sujeita, o que, todavia, alerta ele, não exclui o diálogo com outros povos e a universalidade dos princípios gerais da ciência.

Cumpre ao menos mencionar de passagem que esse ponto - o da universalidade da ciência - foi mais um elemento, entre outros, de polêmica recorrente de nosso autor com a obra do sociólogo paulista Florestan Fernandes, criticado não apenas por abordar a questão racial brasileira através de teorias importadas, mas por negar, na visão de Guerreiro Ramos, que a sociologia brasileira deveria se pautar pelos problemas sociais nacionais e pelas condições de trabalho científico possíveis no país. Contra o que ele considera que seria uma perspectiva provinciana ("quando se acredita no dever de zelar pela 'pureza' da sociologia" (RAMOS, 1996, p. 26)) e aristocrática (reforçando a distinção entre ciência e senso comum), Guerreiro Ramos defende uma sociologia engajada nos problemas reais do país, uma "autoconsciência social", não-elitista, um "saber vulgarizado" (BARIANI JUNIOR, 2008, p. 157).

Cabe notar como o"cosmopolitismo periférico"(LYNCH, 2013), expresso pela sociologia de Florestan Fernandes representa, de fato, uma decorrência de sua posição intelectual em não considerar as obras que antecederam à institucionalização das ciências sociais no Brasil, a partir dos anos 30-40, como contribuições efetivas ao desenvolvimento científico, mas tão somente como registro histórico do que se pensava no Brasil sobre a política e a sociedade; posição essa, denominada por Wanderley Guilherme dos Santos de "matriz institucional". Em sentido contrário, a proposta de Guerreiro Ramos, de uma sociologia voltada para a solução dos problemas nacionais, levou o sociólgo baiano a examinar o que já havia sido produzido de "ciência social" no país, permitindo que, posteriormente e a partir de sua obra, surgisse o pensamento político brasileiro como campo de investigação científica. Nesse sentido, Wanderley Guilherme dos Santos já notara a decisiva contribuição da obra de Ramos: "[...] sua visão do problema é muito mais elaborada do que as demais [inclusive a de Fernandes], e, de saída, liberta o 
ordenamento da produção intelectual brasileira dos acidentes da cronologia temporal" (SANTOS, 1978, p. 32).

Por fim, cumpre lembrar que o tema da revolução nacional, discutido por ele nos anos 60, também é compreendido por Ramos segundo a perspectiva cópia versus pensamento autêntico. Advogando ser um verdadeiro revolucionário numa época de profundas transformações sociais para o país, esse autor critica não apenas um conjunto de intelectuais "marxistas-leninistas" estrangeiros pelo pendor à ortodoxia e ao dogmatismo, mas principalmente aqueles que, no Brasil, fazem um uso alienado e mecânico dessas teorias.

Através desses textos de conjuntura escritos pouco anos antes do golpe civil-militar (RAMOS, 1961, 1963), o autor quer se diferenciar de outras correntes que militam no processo de mudança social, disputando com elas tanto o diagnóstico da realidade nacional, quanto a capacidade de dirigir essa mudança. Num momento caracterizado por ele como não apenas mais de embate entre a "nação" e a "anti-nação", como em A redução sociológica, mas de criação iminente de uma sociedade socialista, combater os setores reacionários não é a única tarefa. Cumpre disputar com os líderes populares e setores de esquerda, tomados pelo dogmatismo e pela imaturidade política, o direito de orientar a revolução nacional.

Nesse caso, cumpre destacar como a recepção e a interpretação dos textos mais canônicos do marxismo - como os de Marx e Engels, Lenin, Lukacs, entre outros - é mediada pelas circunstâncias históricas peculiares de uma nação, profundamente formada pela dependência colonial (cultural, econômica, científica, etc.). Do mesmo modo, é curioso notar e investigar como Ramos incorpora polemicamente vários intérpretes da tradição marxista mais "heterodoxos" e criticados por muitos intelectuais do Brasil Eduard Bernstein, por exemplo - a fim de formular uma visão crítica e, a seu ver, realista do socialismo brasileiro. Contrariamente aos brasileiros adeptos do "marxismo-leninismo", Ramos rechaça a sociologia marcada pelo "universalismo abstrato", expressão de nossa tendência mimética. Contra isso, ele advoga um conhecimento profundo das especificidades nacionais e o engajamento crítico do intelectual na libertação do país de sua condição de heteronomia.

Como nota André Kaysel (2014), o projeto político de Ramos se filiava ao trabalhismo brasileiro, ainda que visse limites nessa tradição. Teoricamente, sua filiações são múltiplas, 
mas contesta, à esquerda, o marxismo-leninismo do PCB (Partido Comunista Brasileiro) e, à direita, aqueles que querem manter o país sob os laços de dependência colonial. Ramos é um nacionalista de esquerda, que anseia pela integração das classes populares à cidadania e a ruptura do país com o domínio imperialista. Um nacionalismo progressista, avalia Kaysel, e não um nacionalismo conservador como o de Vianna.

A esse respeito, o historiador Boris Fausto nota como a emergência de um discurso nacionalista no Brasil se deu de modo diverso do nacionalismo dos países centrais:

A idéia de nação integrou as correntes revolucionárias européias, entre as últimas décadas do século XVIII e meados do século XIX, que lutavam contra o absolutismo monárquico. Os ideais nacionais associavam-se aos novos princípios de liberdade e igualdade que deveriam definir as relações entre os povos. Completado o ciclo revolucionário, o nacionalismo tomou em grandes linhas outro rumo, sendo instrumentado por nações que chegaram mais tarde à mesa do banquete europeu, como é o caso doa Itália e da Alemanha. No Brasil e em outros países do chamado Terceiro Mundo, a questão nacional tinha outra dimensão, sendo apropriada tanto pela direita, quanto pela esquerda, com diferentes matizes que vão do tradicionalismo ufanista à luta de libertação nacional contra o imperialismo. Daí não ser possível mencionar o nacionalismo como um elemento típico da direita, pois ele transita, ainda que com marcas próprias, de um campo a outro do universo político. (FAUSTO, 2001, p. 16).

Kaysel pondera que a passagem do nacionalismo conservador de Vianna, com quem Ramos se identifica na crítica à inteligência brasileira, para o nacionalismo popular é facilitada pelas próprias condições reais do país, quer dizer, uma economia e uma nação que permanece dependente do exterior e que só a partir de 1930 começa a contestar, mas ainda parcialmente, esses laços de dependência.

A revolução proposta por Guerreiro Ramos tem como idéias centrais o desenvolvimento, industrialização e o ativismo popular. No caso, o povo não é visto como uma massa amorfa e apática, mas como portador de demandas já despertas e que necessitam de uma orientação política e científica. Importante mencionar que, ainda que adote, nessas obras dos anos 60, o conceito de classes sociais, além de outros da tradição marxista, esse autor não abandona as categorias de povo e nação, em geral, criticadas por essa tradição de pensamento.

Pelos argumentos por ora apresentados, verifica-se a centralidade da imitação no pensamento desse autor, o que talvez possa ser explicado pela própria importância que 
o conceito de nação adquiriu nesse período, o do nacional desenvolvimentismo. Basta lembrar que é o próprio Guerreiro Ramos quem afirma categoricamente que à época o país vivia o enfrentamento trágico entre a "nação" e a "anti-nação", fruto da cópia e da heteronomia.

\section{Conclusão: a imitação e o "fantasma da condição periférica"}

Pode-se dizer que a imitação se constituiu historicamente em um dos temas prediletos e um dos topos argumentativo da inteligência nacional (motivo de crítica a seus adversários), desde antes de Oliveira Vianna e talvez a se prolongar para além da atualidade. Mais do que isso, ela é um elemento estruturante do próprio campo do pensamento político brasileiro, de tal modo que a constituição desse campo de estudos teve que se haver com ela, como é o caso conspícuo de Vianna e Ramos. Dizendo de outro modo, os autores aqui estudados, críticos de uma suposta tendência mimética de nosso povo e, principalmente de nossas elites, foram também pioneiros no reconhecimento de que havia uma tradição genuína de pensamento político no país, que não se resumia, como de regra, a elogiar e copiar as ideias de alhures. Desta feita, permitiram, através inclusive de sua própria iniciativa, a transformação da mentalidade predominante no país, de modo que o passado intelectual brasileiro fosse considerado, doravante, no mesmo patamar que a ciência produzida nos países centrais.

Não é possível discutir aqui todas as razões que explicam a permanência da imitação no pensamento brasileiro, mesmo depois quando a autonomia nacional já não é mais (ou não é na mesma medida) um valor político a orientar a realidade brasileira. Todavia, enquanto hipótese de trabalho, inspiramo-nos na ideia proposta por Lynch acerca do pensamento político brasileiro, qual seja: a de que no Brasil paira ainda o "fantasma da condição periférica". Sobre essa ideia, o autor sintetiza:

[...] no Brasil, suas elites sempre consideraram seus produtos intelectuais mais ou menos inferiores àqueles desenvolvidos na Europa e nos Estados Unidos, em consequência de uma percepção mais ampla do caráter periférico do país. (LYNCH, 2013, p. 730-731).

Esse estudioso examina, nesse sentido, porque é comum utilizar o termo "teoria" ao nos referirmos aos textos clássicos da política oriundos das nações centrais, como os de Maquiavel, Habermas, etc., e ao tratar dos textos nacionais também considerados 
clássicos, como os de Visconde do Uruguai, Gilberto Freyre, etc., falamos em "pensamento". Até mesmo o presente texto adotou semelhante terminologia?.

A justificativa para tal distinção terminológica repousaria em duas razões, esclarece Lynch. A primeira, de que a teoria seria mais sistemática e coerente do que o pensamento, mais voltado para a prática política, e, a segunda, de que a teoria seria um saber de validade universal, ao passo que o pensamento, apenas de validade nacional. Ambos argumentos, em suma, atestam portanto que os "teóricos" são autores mais relevantes quando comparados aos"pensadores" da política, pois as obras dos últimos não podem ser equiparadas às dos primeiros no que tange à sistematicidade, originalidade e profundidade.

Ademais, Lynch sugere que há uma terceira razão relevante para se diferenciar a "teoria política" europeia e estadunidense do"pensamento político"brasileiro, argentino, cubano, etc. É a percepção, como se disse anteriormente, de que nesses últimos países, isto é, nas colônias, há um "atraso cultural" que se manifesta nas obras de "interpretação" política. O "pensamento" brasileiro, nessa linha interpretativa que se fundamenta numa filosofia da história evolucionista e teleológica, seria uma espécie de repetição cultural e atrasada da teoria dos países do Atlântico Norte.

Percebe-se, em suma, como que, a despeito de ter-se tornado independente politicamente de sua metrópole, o Brasil permanece com uma marca de origem, o fantasma da inautenticidade, da cópia, do transplante cultural, etc. Sob outra perspectiva, o "dilema do Mazombo" descrito por Joaquim Nabuco, isto é, a angústia em pertencer materialmente ao Novo Mundo mas ainda estar ligado espiritualmente ao Velho Mundo, reitera o diagnóstico aqui proposto de que o pensamento (ou deveríamos dizer a teoria?) brasileiro teve que se haver recorrentemente com a ideia da inautenticidade.

Se essa condição explica a existência de que por aqui se produz " pensamento", mas não "teoria", gerada nos países ditos desenvolvidos, sendo a primeira uma espécie de "rescaldo" da segunda (LYNCH, 2013, p. 735), ela também pode explicar porque a imitação é um tema recorrente na história das ideias políticas brasileiras, mesmo após nossa Independência. Fazer a crítica à tendência mimética dos brasileiros seria um modo de denunciar os critérios questionáveis e os preconceitos comumente recorrentes ao se avaliar a cultura nacional.

7 Esse autor destaca a variação terminológica da área - pensamento brasileiro, pensamento social brasileiro, pensamento político-social brasileiro, expressões tomadas acriticamente como sinônimos. Adotamos aqui, como se viu, para fins de uniformização do texto, a expressão "pensamento político brasileiro". 
No entanto, o modo como se concebia a relação entre os "pensamentos"formulados no Brasil e as"teorias" importadas do estrangeiro, ao longo do período republicano, não permaneceu estático. Conforme argumenta Lynch, entre 1880 e 1930, prevalece um padrão cultural descrito por ele como "cosmopolitismo periférico" (em que predomina um sentimento de inferioridade na inteligência brasileira em relação à cultura europeia e norte-americana) e, entre 1922 e 1970, o "nacionalismo periférico"(em que se começa a questionar esse sentimento de inferioridade).

No "cosmopolitismo periférico", considera-se de modo pessimista que o Brasil carece, a rigor, de história, pois quem faz a história é o povo e esse pressupõe uma unidade e originalidade cultural que o país ainda não teria. Não havendo povo nem história, a tarefa que supostamente cabia ao país era seguir os modelos culturais estrangeiros, não a de contribuir, de modo original, naquele momento como protagonista na história universal. Mesmo que alguns intelectuais do país tenham procurado encontrar uma centelha de pensamento genuíno por aqui, avalia Lynch, preponderou a atitude de renegar e/ou subestimar a produção intelectual brasileira vis-à-vis à "teoria" e à "filosofia" produzidas nos países centrais.

Já segundo a perspectiva do "nacionalismo periférico", aberta pela crítica ao evolucionismo e ao etnocentrismo comum aos intelectuais até os anos 20, a trajetória singular de cada país começa a ser valorizada, bem como o "pensamento" ou "teoria" formulada em cada um deles. Desta feita, são publicadas não apenas obras que proclamam pretender conhecer o "país real", como também buscam identificar uma linhagem de pensamento autêntico no Brasil, como são os casos dos autores por nós estudados.

É sob essa chave interpretativa - a do "nacionalismo periférico" - que é possível aproximar Oliveira Vianna de Guerreiro Ramos, o segundo seguindo as pegadas inovadoras do primeiro, ainda que ideologicamente subsistam diferenças significativas entre o pensamento deles. Tanto o pensador fluminense, quanto o sociólogo baiano são profundamente críticos em relação à produção científica do país, caracterizada, via de regra, como imitação ingênua e mecânica de teorias "alienígenas". Todavia, como nota Lynch, diferentemente daqueles que ainda operavam segundo o "cosmopolitismo periférico"e mesmo aqueles que já pensavam ser necessário criar um pensamento brasileiro original (supondo que esse ainda não existia), Vianna e Ramos não relegam ao esquecimento a produção intelectual do passado, identificando nela germes de um pensamento rico 
e autêntico. Lynch defende que essa nova postura diante da realidade nacional, ainda que não isenta de algum etnocentrismo, permitiu a emergência posterior de uma nova área de estudos, o pensamento político brasileiro, fundado mais solidamente, por assim dizer, a partir do mapeamento realizado por Wanderley Guilherme dos Santos sobre a "imaginação política" brasileira, no final dos anos 60.

Isso significa que enquanto o pensamento político brasileiro foi tomado como uma cópia imperfeita do pensamento europeu e norte-americano, ele próprio não foi estudado adequadamente e a superação desse limite requereu que a ideia de imitação fosse não desconsiderada, mas relativizada, ao mesmo tempo, que funcionou retoricamente a esses autores nas contendas argumentativas que empreenderam com seus pares. O movimento argumentativo a partir da idéia de cópia é duplo: por um lado, funciona como instrumento de crítica aos adversários e, por outro lado, serve para estabelecer uma certa tradição de pensamento político nacional.

Precisamente por isso, procuramos ao longo deste trabalho explorar - mais do mapear sistematicamente - as possibilidades hermenêuticas de compreensão do Brasil a partir da ideia de imitação. Embora, julguemos que existam muitas possibilidade, muitas questões decorrentes da importância da imitação na cultura e na política brasileira ainda não foram satisfatoriamente respondidas.

Uma primeira questão é se a imitação é um topos argumentativo claramente conservador, como sugere Ricupero (2010)?

Fausto igualmente parece conceber esse discurso como próprio dos setores conservadores:

Um dos argumentos centrais da cerrada critica que os pensadores autoritários faziam ao liberalismo consistia em afirmar que o liberalismo era uma doutrina exótica, inaplicável à realidade brasileira. Notemos, de passagem, que a expressão "doutrina exótica" teve longa vida no país, sendo um instrumento utilizado, com freqüência pelas forças políticas conservadoras, em seu ataque ao comunismo de inspiração soviética. (FAUSTO, 2001, p. 52).

Será esse o caso um caso geral na utilização do argumento da cópia? Infelizmente, como não se fez aqui nem uma análise em profundidade de uma obra específica, nem um análise do uso desse argumento por outros autores, que não Vianna e Ramos, não é possível responder essa pergunta. 
Um segundo problema de pesquisa que deveria ser enfrentado diz respeito à atualidade (ou não) do argumento da cópia. Já que a própria noção de nação passou a um plano secundário da inteligência brasileira a partir dos anos de 1970 (PÉCAUT, 1990; LAHUERTA, 2010), sendo gradualmente substituída pelo discurso sobre e pela democracia, terá perdido sentido a ideia de autenticidade da cultura brasileira? Nesse caso, a história das ideias políticas no Brasil poderia identificar um gradativo esquecimento dessa problemática.

Por fim, uma terceira linha de pesquisa que mereceria ser examinada se refere a história das ideias políticas de outras nações, tanto aquelas que foram colônias, quanto aquelas que, por razões históricas específicas, mesmo não sendo colônias, não vieram a estar no centro da civilização europeia. Desse modo, uma análise comparada das ideias políticas brasileiras com as chilenas e as portuguesas, por exemplo, poderia nos informar melhor sobre a pertinência e o alcance da ideia da cópia nessas outras experiências nacionais.

\section{Referências}

BARIANI JUNIOR, E. Guerreiro Ramos e a redenção sociológica: capitalismo e sociologia no Brasil. 2008. 329 f. Tese (Doutorado em Sociologia)-Universidade Estadual Paulista Júlio de Mesquita Filho, Araraquara, 2008.

BRANDÃO, G. Linhagens do pensamento político brasileiro. São Paulo: Hucitec, 2010.

CANDIDO, A. Formação da literatura brasileira: momentos decisivos (1750-1880). 12. ed. São Paulo: FAPESP, 2009.

FAORO, R. Existe um pensamento político brasileiro? São Paulo: Ática, 2007.

FAUSTO, B. O pensamento nacionalista autoritário (1920-1940). Rio de Janeiro: Jorge Zahar, 2001.

KAYSEL, A. Epistemologia conservadora, política radical: história das ideias e projeto político na obra de Guerreiro Ramos. In: ENCONTRO DA ASSOCIAÇÃO BRASILEIRA DE CIÊNCIA POLÍTICA, 9., 2014, Brasília. Anais... [S.I.]: ABCP, 2014.

KOSELLECK, R. Futuro passado: contribuição à semântica dos tempos históricos. Rio de Janeiro: EDUERJ, 2006.

LAHUERTA, M. Intelectuais e resistência democrática: vida acadêmica, marxismo e política no Brasil. Cadernos AEL, v. 8, n. 14, p. 57-92, 2010.

LYNCH, C. Por que Pensamento e não Teoria? A imaginação político-social brasileira e o fantasma da condição periférica (1880-1970). Dados: Revista de Ciências Sociais, v. 56, n. 4, p. 727-767, 2013. 
PÉCAUT, D. Intelectuais e a política no Brasil: entre o povo e a nação. São Paulo: Ática, 1990.

RAMOS, G. Introdução crítica à sociologia brasileira. Rio de Janeiro: Editorial ANDES Limitada, 1957.

RAMOS, G. A crise do poder no Brasil (problemas da revolução nacional brasileira). Rio de Janeiro: Zahar Editores, 1961.

RAMOS, G. Mito e verdade sobre a revolução brasileira. Rio de Janeiro: Zahar Editores, 1963.

RAMOS, G. A redução sociológica. 3. ed. Rio de Janeiro: Editora UFRJ, 1996.

RICUPERO, B. Da formação à forma: ainda as 'ideias fora do lugar'. Lua Nova, v. 73, p. 59-69, 2008.

RICUPERO, B. O conservadorismo difícil. In: FERREIRA, G. N. Revisão do pensamento conservador: ideias e políticas no Brasil. São Paulo: Hucitec, Fapesp, 2010.

RICUPERO, B. O lugar das ideias: Roberto Schwarz e seus críticos. Sociologia \& Antropologia, v. 3, n. 6, p. 525-556, 2013.

SANTOS, W. Ordem burguesa e liberalismo político. São Paulo: Duas Cidades, 1978.

SCHWARZ, R. As ideias fora do lugar. Estudos Cebrap, v. 3, p. 150-161, 1973.

VIANNA, L. Americanistas e iberistas: a polêmica de Oliveira Vianna com Tavares Bastos. In: VIANNA, L. A revolução passiva: iberismo e americanismo. 2. ed. Rio de Janeiro: Revan, 2004. p. 151-194.

VIANNA, O. O idealismo da constituição. 2. ed. aumentada. São Paulo: Companhia Editora Nacional, 1939.

VIANNA, O. Instituições políticas brasileiras. 2. ed. São Paulo: José Olympio Editora, 1995.

VIANNA, O. Populações meridionais do Brasil. Brasília: Senado Federal, Conselho Editorial, 2005.

Recebido: 22 ago., 2016

Aceito: 25 nov., 2016 